\title{
Trends in Microorganisms Isolated from Blood Cultures at a Veterans Hospital from 2012 to 2015
}

\author{
Misuk Ji ${ }^{1}$, Youn Mi \\ $\mathrm{Choi}^{1}$, Eunsin Bae ${ }^{1}$, and \\ Choon-Kwan Kim ${ }^{2}$ \\ Departments of ${ }^{1}$ Laboratory \\ Medicine and ${ }^{2}$ Internal \\ Medicine, VHS Medical \\ Center, Seoul, Korea
}

Blood culture is important to detecting bacteremia and fungemia in patients with suspected sepsis. We observed a four-year trend of blood culture isolates in the frequency by age group and in vitro antimicrobial susceptibility patterns obtained at VHS Medical Center, the largest veterans hospital in Korea. Blood cultures collected between 2012 and 2015 were analysed retrospectively. Of 68,352 blood specimens, 7,901 isolates were identified during the study period. Seventy-two percent of the isolates were gram-positive cocci, $18 \%$ were gram-negative rods, and $6 \%$ were fungi. The frequency of bacteremia/fungemia in patients who were $80-89$ years old was $43.8 \%$, the highest rate among all age groups, and the mean age of patients diagnosed by blood culture was 77 years old. Coagulase-negative staphylococcus (52.3\%), Staphylococcus aureus (8.3\%), enterococci (7.5\%), Escherichia coli (6.4\%), and Klebsiella pneumoniae (3.9\%) were the bacteria most commonly isolated. The percentage of methicillin-resistant $S$. aureus increased in $2015(76 \%)$ relative to that in 2012-2014 (63\%-65\%), and that of vancomycin-resistant Enterococcus faecium was $17 \%-22 \%$ with no significant changes through time. Among the gram-negative isolates, the ciprofloxacin resistance rate increased to $51.4 \%$ (E. coli) and 31.1\% (K. pneumoniae) in 2015, but imipenem or ertapenem resistance was still very rare, with resistance rates of less than $0.5 \%$. Acinetobacter baumannii showed a high rate of resistance (over 70\%) to imipenem and ciprofloxacin throughout the study. In Pseudomonas aeruginosa, the resistance rates of imipenem and ciprofloxacin increased dramatically over time. This analysis confirmed a decrease in antimicrobial susceptibility of gram-negative rods isolated by blood culture.

(J Lab Med Qual Assur 2017;39:141-146)

Key Words: Blood culture, Bacteremia, Antimicrobial susceptibility

Received April 28, 2017, Revision received July 19, 2017, Accepted August 1, 2017
혈액배양검사는 혈류감염의 신속하고 정확한 진단을 위한 유일한 표준검사법이며, 패혈증이 의심되는 환자에서 원인균 의 검출과 동정, 항균제 감수성 여부를 파악하는데 매우 중요 하다[1]. 그러나 혈액배양에서 균 분리 빈도 및 병원균 분포, 항균제 감수성 결과 양상은 병원과 환자의 특성, 지역, 시기에 따라 다른 양상을 보일 수 있다. 국내에서 균혈증 원인균 및 항 균제 감수성 양상에 대해 과거 여러 차례 보고된 바 있으나, 최 근의 추세는 별도 보고된 바 없다[2-5]. 중앙보훈병원은 국가 유공자를 주로 진료하는 공공의료기관으로 2011년 9월 1,000 병상으로 확대 개원하였다. 이에 타 기관에 비해 여러 질환을 동반한 고령의 환자가 많은 본 기관에서 4 년간의 혈액배양 현 황을 조사하여 보았다.

2012년 1월부터 2015년 12월까지 성인 환자에서 총 68,352
건의 혈액배양검사가 의뢰되었다. 호기성 배지와 혐기성 배지 1 세트 의뢰를 1 건으로 계수하였으며, 연령대별 혈액배양 의뢰 건수는 50대 이하 3,003 (4.4\%), 60대는 10,032 (14.7\%), 70 대는 23,976 (35.0\%), 80대는 26,709 (39.0\%), 90대 이상은 4,632 (6.8\%)건이었다. 연도별로 한 환자에서 반복적으로 동 일한 균이 분리된 경우에는 처음 양성으로 보고된 결과만을 분 석에 포함하였다. 혈액배양검사를 위하여 BacT/Alert FA/ $\mathrm{FN}$ (bioMérieux Inc., Durham, NC, USA)을, 균의 동정과 항균제 감수성 검사를 위하여 Vitek 2 system (bioMerieux, Marcy-l'Etoile, France) 또는 MicroScan WalkAway-96 (Beckman Coulter, West Sacramento, CA, USA)를 사 용하였다. 결과분석 시 오염균의 가능성이 높은 coagulasenegative staphylococcus (CNS)의 경우 집합적으로 하나의 
그룹으로 취급하였으며, streptococcus의 경우 Streptococcus pneumoniae, S. agalactiae, S. pyogenes를 제외한 나머지 균 들은 viridans streptococci로 분석하였다. 혈액배양에서 분리 된 균의 항균제 감수성은 Clinical and Laboratory Standards Institute [6]에서 제시된 기준에 따랐으며, 통계분석은 엑셀 프로그램(Microsoft, Redmond, WA, USA)을 이용하였다. 연도별로 분리된 혈액배양 균종의 연령대별 빈도 및 항균제 감 수성의 변화 추이를 조사하였다.

연도별 혈액배양 분리 균수는 2012년 1,589개, 2013년 1,926 개, 2014년 2,211개, 2015년 2,175개로 4년 동안 중복 을 제외하고 총 7,901 개의 균이 분리되었다(Table 1). 균주 분리 환자들의 평균 연령士표준오차는 2012년 77.8土9.1세,

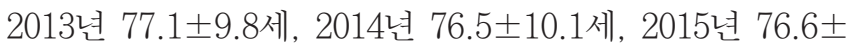
10.1세였으며, 남성의 비율은 2012년 88.5\%, 2013년 86.6\%, 2014 년 $87.4 \%, 2015$ 년 $87.4 \%$ 로 대부분 남성 환자였다. 분 리 균주의 연령대별 비율을 조사한 결과, 50 대 이하 $4.0 \%$, 60 대 $18.9 \%, 70$ 대 $28.7 \%, 80$ 대 $43.8 \%, 90$ 대 $4.6 \%$ 로 80대 의 비율이 가장 높았다. 연령대별 혈액배양 양성률은 50 대 이 하 $10.6 \%, 60$ 대 $14.9 \%, 70$ 대 $9.5 \%, 80$ 대 $13.0 \%, 90$ 대 이상 $7.9 \%$ 로 의뢰건수 대비 60 대의 분리율이 가장 높았고 다음으 로 80대가 높았다. 연간 입원 환자수로 보정한 분리 균수는 50 대 이하 $0.736,60$ 대 $1.534,70$ 대 $1.903,80$ 대 $4.654,90$ 대 이
상 6.419로, 연령대가 증가할수록 입원환자 수 대비 혈액배양 분리 균수가 증가하였다.

전체 분리건수는 2012년부터 2014년까지 완만히 증가 하다가 2015년에 약간 감소하였다. 그람양성 구균은 전체 의 $72.0 \%$ 를 차지하여 기존 국내 보고(55.1\%-56.3\%)에 비 해 높았으며, 그람음성 간균은 $17.8 \%$ 를 차지하여 기존 보 고(33.6\%-38.4\%)에 비하여 다소 낮았다[2-5]. 그러나 그 람음성 간균의 비율은 2012년 18.0\%, 2013년 17.5\%, 2014 년 $15.5 \%, 2015$ 년 $20.2 \%$ 로 2015년에 약간 증가하는 추세 를 보였다. 진균은 5.7\%로 기존 보고(2.8\%-3.8\%)에 비해 높 은 편이었고 그 외 그람양성 간균이 $3.0 \%$, 혐기성 균이 $1.5 \%$ 를 차지하였다. 다빈도 분리 균종 순위는 $\mathrm{CNS}(52.3 \%)$, Staphylococcus aureus (8.3\%), enterococci (7.5\%), Escherichia coli (6.4\%), Klebsiella pneumoniae (3.9\%) 순 이었다. CNS의 분리비율이 기존 국내 보고(24.4\%-41.0\%) 에 비하여 다소 높았고, E. coli의 비율이 $6.4 \%$ 로 기존 보고 (13.5\%-16.9\%)의 절반에 불과하였다[2-5]. S. aureus의 비율 은 기존 보고(7.5\%-11.5\%)와 유사하였으며 K. pneumoniae 는 $3.9 \%$ 로 기존 보고(4.1\%-7.5\%)보다 낮은 편이었다[25]. 진균 분리주 중에서는 Candida parapsilosis가 29.9\% 를 차지하여 C. albicans (21.2\%)보다 더 많은 빈도로 분리 되었다. 연령대별 다빈도 분리 균종을 추가 분석한 결과, 전

Table 1. Frequency of microorganisms isolated from blood cultures from 2012 to 2015 in comparison with that from previous Korean studies

\begin{tabular}{|c|c|c|c|c|c|c|c|c|}
\hline \multirow{2}{*}{ Organisms } & \multicolumn{4}{|c|}{ Year } & \multirow{2}{*}{ Total \% } & \multirow{2}{*}{ Oh et al. [2] } & \multirow{2}{*}{ Kim et al. [3] } & \multirow{2}{*}{ Kim et al. [4] } \\
\hline & 2012 & 2013 & 2014 & 2015 & & & & \\
\hline Gram-positive cocci & $1,195(75.2)$ & $1,377(71.5)$ & $1,597(72.2)$ & $1,516(69.7)$ & 72.0 & 56.3 & 55.1 & $\mathrm{NA}$ \\
\hline CNS & $840(52.9)$ & $1,025(53.2)$ & $1,185(53.6)$ & $1,085(49.9)$ & 52.3 & 37.1 & 24.4 & 23.6 \\
\hline Enterococci & $110(6.9)$ & $137(7.1)$ & $168(7.6)$ & $181(8.3)$ & 7.5 & $1.9^{*}$ & $3.7^{\star}$ & $3.4^{*}$ \\
\hline Others & $19(1.2)$ & $19(1.0)$ & $27(1.2)$ & $30(1.4)$ & 1.2 & NA & NA & NA \\
\hline Gram-positive rod & $30(1.9)$ & $56(2.9)$ & $96(4.3)$ & $58(2.7)$ & 3.0 & NA & 5.0 & NA \\
\hline Gram-negative cocci & $1(0.1)$ & 0 & $2(0.1)$ & $2(0.1)$ & 0.1 & NA & NA & NA \\
\hline Gram-negative rod & $286(18.0)$ & $338(17.5)$ & $343(15.5)$ & $439(20.2)$ & 17.8 & 33.6 & 38.4 & NA \\
\hline Anaerobes & $22(1.4)$ & $38(2.0)$ & $20(0.9)$ & $37(1.7)$ & 1.5 & NA & 2.7 & NA \\
\hline Fungi & $55(3.5)$ & $117(6.1)$ & $153(6.9)$ & $123(5.7)$ & 5.7 & 3.8 & 2.8 & NA \\
\hline Total & 1,589 & 1,926 & 2,211 & 2,175 & 7,901 & & & \\
\hline
\end{tabular}

Abbreviations: NA, not available; CNS, coagulase-negative staphylococci.

*The frequency of Enterococcus faecium is presented. 
체 추세분석결과와 비슷하였다. CNS, S. aureus, E. coli, $K$. pneumoniae, 진균에 대해서 각각 연도별, 연령대별 세부분석 결과 상대 빈도는 유사하였다.

주요 그람양성 구균 항균제 내성률 분석결과, 균혈증을 일으 킨 S. aureus 중 옥사실린 내성률은 2012-2014년까지 63\%$65 \%$ 로 유지되다가 2015년 76\%로 증가하였다. 의료 관련 감 염에서 메티실린 내성 황색포도알균(methicillin-resistant $S$. aureus, MRSA)에 의한 균혈증은 메티실린 감수성 황색포도 알균(methicillin-susceptible $S$. aureus) 균혈증보다 사망률 이 유의하게 높은 것으로 알려져 있다. S. aureus 임상분리 주 중 옥사실린 내성률은 90년대 초부터 60\%-70\%로 보고되 었으며, Korean Nationwide Surveillance of Antimicrobial Resistance (KONSAR) 자료에 따르면 1997-2011년 사이 대 체로 60\%-70\%의 일정한 수준을 유지하고 있다[7-9]. Korean Antimicrobial Resistance Monitoring System (KARMS) 자 료에서는 2007-2014년 사이 종합병원 분리주의 60\%-75\%로 보고되었다[10]. 그러나 2012년 이후에는 $60 \%$ 대를 보이고 있 어 본원에서 2015년에 일시적으로 증가한 것인지 추세를 확인 해야 할 것이다. 그 외 균혈증을 일으킨 Enterococcus faecium 중 반코마이신 내성률은 2012-2015년 사이 큰 변화없이 17\%$22 \%$ 사이를 유지하고 있었는데 기존 자료와 비교 시 다소 낮 은 빈도이다. KARMS 자료에 따르면 2007-2014년 종합병원 에서 분리된 $E$. faecium 중 반코마이신 내성률은 26\%-37\% 로 보고되었다[10]. 국내 임상 검체에서 분리된 E. faecium 중 반코마이신 내성률은 2000년대 중반부터 계속 $20 \%$ 를 초과하

A

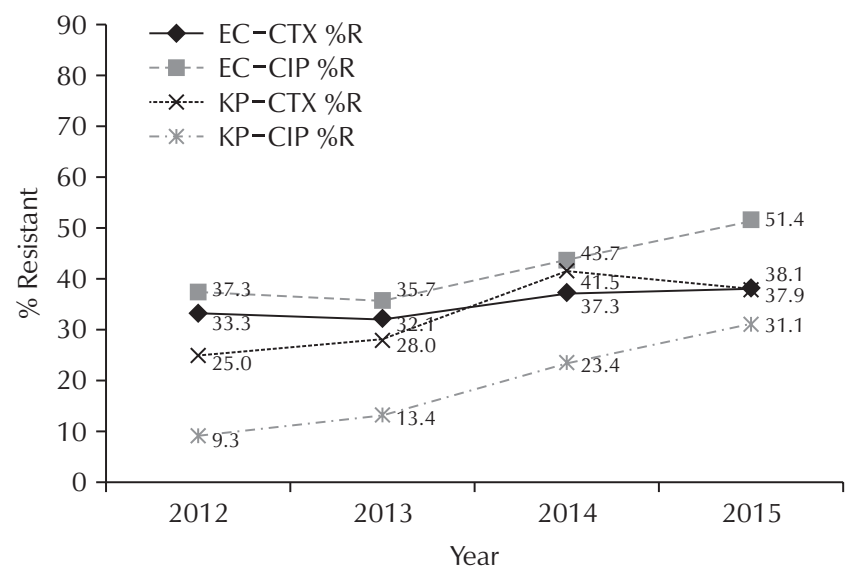

고 있으며 조금씩 상승하는 추세를 보인다[7,8]. 2009년 9개 대학병원 혈액배양에서 분리된 반코마이신 내성 $\mathrm{E}$. faecium (vancomycin-resistant enterococci infection, VRE)의 비율 은 $28.6 \%$ 였다[4]. 또한 한 대학병원에서 13 년간 혈액배양에 서 분리 균주 추세를 조사한 결과 1998년에는 VRE의 비율이 $0 \%$ 였으나 2000년 중반 이후 점차 증가하여 2010년 35.3\%까 지 상승하였음을 보고하였다[3].

장내세균속 그람음성 간균 항균제 내성률 분석결과, 균 혈증을 일으킨 E. coli의 시프로플록사신 내성률은 2012년 $37.3 \%$ 에서 2015년 51.4\%로 급격히 증가하였다(Fig. 1A). $\mathrm{KONSAR}$ 자료에 따르면 국내 병원 임상 검체에서 분리된 E. coli의 퀴놀론계 항균제 내성률은 2007년 27\%, 2011년 $36 \%$ 였다 [8,9]. 또한 KARMS 자료에서는 2012년 이후 40\%$45 \%$ 의 내성률을 나타내었다[10]. 한 대학병원에서 혈액분 리 E. coli 균주의 시프로플록사신 내성률이 1998년 20\%에 서 2010년 35\%로 증가하였다고 보고한 바도 있다[3]. 퀴놀론 계 내성률 증가는 항균제 사용량 증가와 관련되어 있을 가능 성이 높다[3,11]. K. pneumoniae의 시프로플록사신 내성률 의 경우, 2012 년 9.3\%에서 2015년 31.1\%로 증가하였다. 그 러나 KONSAR 자료에서는 2007년, 2011년 모두 27\%였고, $\mathrm{KARMS}$ 자료에서도 25\%-30\% 사이였다[8-10]. 기존 자료와 비교해 보면 K. pneumoniae 균주의 퀴놀론계 내성률이 타 기 관에 비하여 낮은 편이었다가 유사한 수준으로 증가하였다고 볼 수 있을 것이다. 그 외 E. coli와 K. pneumoniae 균주의 세 포탁심 내성률은 각각 33.3\%-38.1\%, 25.0\%-41.5\%로 2014

Fig. 1. Four-year trend in antimicrobial resistance rates of isolates of four gram-negative rods. (A) Escherichia coli and Klebsiella pneumoniae. (B) Acinetobacter baumannii and Pseudomonas aeruginosa. Abbreviations: EC, Escherichia coli; CTX, cefotaxime; CIP, ciprofloxacin; IMP, imipenem; KP, Klebsiella pneumoniae; Ac, Acinetobacter baumannii; COL, colistin; CTZ, ceftazidime; PS, Pseudomonas aeruginosa. 
년까지 증가하였다가 2015년에는 소폭 변동 내지는 유지되는 경향을 보였다. 카바페넴 계열 항균제인 이미페넴 또는 얼타페 넴에 내성을 나타내는 E. coli의 비율은 2012년 0.1\%, 2013년 0.3\%, 2014년 0.2\%, 2015년 0.2\%, K. pneumoniae의 비율 은 2012년 0.2\%, 2013년 0.2\%, 2014년 0.3\%, 2015년 0.4\% 로 기존 보고와 유사한 수준으로 드물게 분리되었다[4,8]. Carbapenemase-producing Enterobacteriaceae는 2012년, 2013년 분리되지 않았으며, 2014년에 K. pneumoniae 2건 (OXA-232, KPC-2와 NDM-1)과 E. coli 1건(KPC-2), 2015 년에 K. pneumoniae 3건(모두 $\mathrm{KPC}-2$ )이 분리되었다.

포도당 비발효성 그람음성 간균인 Acinetobacter baumannii의 내성률은 이미페넴 $66.7 \%-72.9 \%$, 시프로플록 사신 71.4\%-78.4\%, 세프타지딤 57.1\%-72.9\%로 이미페넴과 시프로플록사신은 지속적으로 $70 \%$ 대의 높은 내성률을 보이 고 있으며, 콜리스틴은 연도별로 차이를 보이나 $4 \%$ 미만의 대 체적으로 낮은 내성률을 유지 중이다(Fig. 1B). A. baumannii 의 경우 다제내성균이 큰 문제가 되고 있는데 국내 병원 임상 검체 분리주를 대상으로 한 기존 자료에서 2011-2014년 사이 이미페넴 내성률이 $64 \%-82 \%$ 로 매해 증가 추세를 보였으며, 퀴놀론계 59\%-84\%, 세프타지딤 66\%-82\% 콜리스틴 0.7\%$3.4 \%$ 의 내성률을 나타내었다[8,10]. KARMS 자료에서 이미 페넴, 퀴놀론, 세프타지딤 모두 2014년에 내성률이 $80 \%$ 를 초 과하였다[10]. 혈액분리주만 포함한 1,600병상 규모 대학병원 의 연구에서도 2010 년 이미페넴, 시프로플록사신 모두 $70 \%$ 정도의 내성률을 나타내는 것으로 보고되었다[3]. 혈액분리주 만 포함한 한 연구에서도 이미페넴에 대한 내성률이 점점 증가 하여 2012년에 79\%에 달하였다[5]. 본 연구에서 시간에 따라 내성률이 변화하는 양상은 관찰되지 않았으나 A. baumannii 의 경우 이미 내성률이 높은 상태가 유지되고 있음을 확인할 수 있었다. Pseudomonas aeruginosa의 내성률은 이미페넴 26.5\%-42.2\%, 시프로플록사신 $11.8 \%-44.4 \%$, 세프타지딤 $13.6 \%-34.4 \%$ 로 이미페넴과 시프로플록사신의 내성 비율이 4 년간 급격히 증가하였다. 기존 자료에서 2011-2014년 사이 이 미페넴 내성률은 22\%-33\%, 퀴놀론계 32\%-41\%, 세프타지딤 20\%-23\%로 보고되었는데 지속적인 감염관리 강화와 함께 추 이 관찰이 필요할 것으로 생각된다 $[8,10]$. 콜리스틴은 $3 \%$ 미 만으로 기존 보고( $1.6 \%-3.8 \%, \mathrm{KARMS})$ 와 유사한 수준의 낮 은 내성률을 유지 중이다[10].

균혈증 환자의 효과적인 치료를 위해서는 해당기관에서 흔 하게 분리되는 혈액배양 병원균의 분포와 항균제 감수성에 대 한 정보가 중요하다. 2012-2015년 사이 4년간 혈액배양에서 분리된 균의 종류 및 연령대별 분리 빈도 등을 조사한 결과, 혈 액배양 양성 환자 중 50 대 이하의 비율은 $4.0 \%$ 로, 대부분의
환자가 60세 이상의 고령 환자인 점이 타 병원과 다르다. 연 간 입원 환자수를 이용하여 연령대별 분리 균수를 보정한 결 과, 연령대가 증가함에 따라 입원 환자수 대비 혈액배양 분리 균수가 증가하는 추세를 보였다. 전체 분리된 균주 중 $\mathrm{CNS}$ 가 절반에 달하였고, S. aureus 및 enterococci가 그 다음으로 매 우 흔하게 분리되어 타 기관 보고결과와 차이를 보였다. CNS 는 혈액배양에서 가장 흔한 오염균이나 동시에 병원 내 감염 (nosocomial infection)의 주요 원인균이므로 혈액배양에서 분 리된 CNS를 어떻게 해석할지에 대해 논란이 있다 $[3,12,13]$. 면역억제 환자 및 혈관 내 카테터를 거치하고 있는 환자들의 경우 더욱 그러하다. 그러나 타 기관에 비해 CNS의 분리 비 율이 더 높고, 오염균으로 흔히 간주되는 Corynebacterium species도 많이 분리되었기 때문에 혈액배양 검체 채취방법에 대한 교육이 강화되어야 할 것으로 생각된다.

다제내성균 중 MRSA의 비율이 2015년에 상승하여 향후 추 이를 관찰하여야 할 필요성이 있으며, $\mathrm{VRE}$ 는 비슷한 비율로 유지 중이고 카바페넴 내성 장내세균속의 비율은 매우 낮은 수 준이다. 포도당 비발효성 그람음성 간균 중 P. aeruginosa의 경우 이미페넴, 시프로플록사신 등에 대한 내성률이 급격히 증 가 중이므로 향후 추이 관찰이 필요하다. A. baumannii의 경 우 이미페넴, 시프로플록사신, 세프타지딤 등에 내성을 보이는 균주의 비율이 이미 높은 상태이다. 다제내성 A. baumannii 는 의료환경에서 오랫동안 생존 가능하고 중환자실을 중심으 로 감염이 발생하므로 적절한 항균제의 사용 및 감염관리 대책 을 강화할 필요가 있다.

이 연구의 제한점은 환자의 상병명, 진료과, 입원기간 등에 따른 세부분석은 하지 못하였고 연령대별 세부분석만 시행하 였다는 점이다.

결론적으로 2012년부터 2015년까지 4년간 한 공공의료기 관에서 혈액배양 추세를 분석한 결과 $\mathrm{CNS}$ 등 그람양성 구 균과 진균의 비율이 타기관에 비하여 높았고, E. coli, K. pneumoniae 등 그람음성 간균의 비율이 상대적으로 낮았다. 또한 대체적으로 그람음성 간균의 항균제 감수성이 감소하는 추세인 것을 확인하였다.

\section{감사의 글}

이 논문은 2016년도 중앙보훈병원 연구개발비 지원을 받아 수행된 연구과제이다(VHSMC16020).

\section{REFERENCES}

1. Aronson MD, Bor DH. Blood cultures. Ann Intern Med 


\section{Journal of LABORATORY MEDICINE and QUALITY ASSURANCE}

Misuk Ji et al • Trends in Blood Cultures over 4 Years

1987;106:246-53.

2. Oh TS, Nam YS, Kim YJ, Yang HS, Lee MY, Gu HJ, et al. Trends in bloodstream infections at a Korean university hospital between 2008 and 2013. Ann Clin Microbiol 2015;18:14-9.

3. Kim NH, Hwang JH, Song KH, Choe PG, Park WB, Kim ES, et al. Changes in antimicrobial susceptibility of blood isolates in a university hospital in South Korea, 19982010. Infect Chemother 2012;44:275-81.

4. Kim HJ, Lee NY, Kim S, Shin JH, Kim MN, Kim EC, et al. Characteristics of microorganisms isolated from blood cultures at nine university hospitals in Korea during 2009. Korean J Clin Microbiol 2011;14:48-54.

5. Shin KA, Shin KS, Hong SB. Change pattern of species and antimicrobial susceptibility of microorganisms isolated from blood culture during 5 years: 2008-2012. J Exp Biomed Sci 2013;19:245-53.

6. Clinical and Laboratory Standards Institute. Performance standards for antimicrobial susceptibility testing. 26th ed. Wayne (PA): Clinical and Laboratory Standards Institute, 2016.

7. Kim MN. Multidrug-resistant organisms and healthcareassociated infections. Hanyang Med Rev 2011;31:141-52.

8. Yong D, Shin HB, Kim YK, Cho J, Lee WG, Ha GY, et al. Increase in the prevalence of carbapenem-resistant
Acinetobacter isolates and ampicillin-resistant nontyphoidal Salmonella species in Korea: a KONSAR study conducted in 2011. Infect Chemother 2014;46:84-93.

9. Lee K, Lee MA, Lee CH, Lee J, Roh KH, Kim S, et al. Increase of ceftazidime- and fluoroquinolone-resistant Klebsiella pneumoniae and imipenem-resistant Acinetobacter spp. in Korea: analysis of KONSAR study data from 2005 and 2007. Yonsei Med J 2010;51:901-11.

10. Korea Centers for Disease Control and Prevention. Korean Antimicrobial Resistance Monitoring System (KARMS) 2014 annual report. http://cdc.go.kr/CDC/ $\mathrm{cms} / \mathrm{cmsFileDownload}$.jsp?fid=136\&cid=21224\&fieldName= attachGrp\&index=11 (Accessed July 18, 2017).

11. Jun KI, Koo HL, Kim MK, Kang CK, Kim MJ, Chun $\mathrm{SH}$, et al. Trends in antibiotic use in a single university hospital. Korean J Nosocomial Infect Control 2013;18:4450.

12. Favre B, Hugonnet S, Correa L, Sax H, Rohner P, Pittet D. Nosocomial bacteremia: clinical significance of a single blood culture positive for coagulase-negative staphylococci. Infect Control Hosp Epidemiol 2005;26:697-702.

13. Beekmann SE, Diekema DJ, Doern GV. Determining the clinical significance of coagulase-negative staphylococci isolated from blood cultures. Infect Control Hosp Epidemiol 2005;26:559-66. 
4년간 혈액배양에서 분리된 균종 및 항균제 감수성의 추세 분석 지미숙 ${ }^{1}$ 최윤미 ${ }^{1}$ - 배은신 ${ }^{1} \cdot$ 김춘관 $^{2}$

중앙보훈병원 ${ }^{1}$ 진단검사의학과, ${ }^{2}$ 내과

혈액배양검사는 패혈증이 의심되는 환자에서 원인균 검출 및 동정, 항균제 감수성결과 파악에 매 우 중요하다. 고령의 국가유공자를 주로 진료하는 공공의료기관인 중앙보훈병원에서 시행된 혈액 배양검사 결과를 조사하여 보았다. 2012년 1월부터 2015년 12월까지 4년 동안 성인 환자에서 의 뢰된 총 68,352 건의 혈액배양검사 결과를 대상으로 하여 연도별로 분리된 혈액배양 균종의 연령 대별 빈도 및 주요 항균제 감수성의 변화 추이를 조사하였다. 중복을 제외하고 4년간 총 7,901 주 가 분리되었으며 연령대별 비율은 80대가 43.8\%로 가장 높았고 평균 연령은 77.0 세였다. 분리 균 종 순위는 coagulase-negative staphylococci (52.3\%), Staphyloccous aureus (8.3\%), enterococci (7.5\%), Escherichia coli (6.4\%), Klebsiella pneumoniae (3.9\%) 순이었다. 메티실린 내성 황색포도상 구균의 비율은 63\%-76\%로 2015년에 증가하였으며, 반코마이신 내성 장구균의 비율은 17\%-22\% 로 큰 변화 없이 유지되었다. 장내세균속의 시프로플록사신 내성률이 지속적으로 증가하여 2015 년 E. coli 51.4\%, K. pneumoniae 31.1\%에 이르렀으나 카바페넴 계열 항균제에는 0.5\% 미만의 낮 은 내성률을 유지하였다. Pseudomonas aeruginosa의 이미페넴, 시프로플록사신 내성률이 급증하 여 2015년 42.2\%, 44.4\%에 이르렀으며 Acinetobacter baumannii의 경우 지속적으로 70\%대의 높 은 내성률을 보였다. 혈액배양 추세분석결과 그람음성 간균의 항균제 감수성이 감소하는 추세인 것 을 확인하였다.

(J Lab Med Qual Assur 2017;39:141-146)

교신저자: 최윤미

우)05368 서울시 강동구 진황도로 61 길 53 , 중앙보훈병원 진단검사의학과

Tel: 02)2225-1459, Fax: 02)2225-4103, E-mail: ymchoi2006@naver.com 